\title{
Risperidone Overdose with Acute Dystonia in Children - A Case Report
}

\author{
Rashmi Patil, Megha P, Chikkanarasa Reddy PS*, Kalpana, Niharika \\ Shetty and Sarala Sabapathy \\ Department of Paediatrics, Bangalore Medical College and Research Institute, \\ Bangalore, India \\ *Corresponding Author: Chikkanarasa Reddy PS, Assistant Professor in \\ Paediatrics, Bangalore Medical College and Research Institute, Bangalore, India.
}

Received: June 01, 2020

Published: June 23, 2020

(C) All rights are reserved by Chikkanarasa

Reddy PS., et al.

\begin{abstract}
Prescription of atypical antipsychotics has been on increasing trend in adults and adolescents. The prescription of atypical antipsychotics to children is very common in developed countries. However, increased trend of atypical antipsychotics in use has also been paralleled by geometric progression in the incidence of intentional and non-intentional overdose. Although, the incidence of extrapyramidal symptoms were associated with lower therapeutic risperidone. In this juxtapose we present a case report findings of risperidone overdose presenting with acute dystonia at lower dosage. Since an overdose is commonly leads to neurological and cardiovascular involvement in children and also serial electrocardial monitoring is warranted. The treatment of risperidone overdose is mainly consists of gastric lavage, supportive therapy etc. Extrapyramidal symptoms associated secondary to risperidone overdose, readily responds to anticholinergics. In Indian context, a very few case fatalities were reported.
\end{abstract}

Keywords: Risperidone; Overdose; Children; Acute Dystonia

\section{Introduction}

Prescription of atypical antipsychotics to children, adolescents and adults has continued to increase over the past decade [1,2]. However, increase in use has also been paralleled by an increase in the incidence of intentional and nonintentional overdose [2,3]. Risperidone is an atypical antipsychotic medication used to treat psychotic illnesses in children and adults $[4,5]$. There are few reports in Indian and Global literature regarding its clinical toxicity profile in younger than 18 years of age [6]. Although, incidence of extrapyramidal symptoms was associated with lower rate of therapeutic risperidone, occurrence of the following over dosage is less clearly defined at global level [5]. Here, we are describing a case report of siblings with alleged history of consumption of risperidone presented in acute dystonia.

\section{Case Report New Findings}

Siblings aged 8 and 5 year old girls were brought by aunts to Paediatric casualty with alleged history of consumption of tablets from their grandmother for the treatment of Psychosis with chief complaints of excessive sleepiness, restlessness and fewer episode of uprolling of eyes at 17 hours post consumption. Retrospectively, it was revealed that, an attempt was made by the family members for mass suicide. Children gave history of swallowing green ( $4 \mathrm{mg}$ ) colour tablets. Risperidone $4 \mathrm{mg}$ tablets around 4 numbers, parents mixed with food and fed to each child (16 mg Risperidone to each child). After investigation, the children were admitted to PICU ward. At admission, the vitals were estimated, found to be stable. Children were drowsy (GCS 12/15) and had slurred speech. Multiple episode of torticollis and uprolling of eye balls lasting for 1 - 2 minutes were noticed. Neurological examination done was found to be within normal limits. Diagnosis of acute dystonia secondary to risperidone ingestion was made during the observational period. Gastric lavage and decontamination, supportive management followed by intravenous Promethazine $25 \mathrm{mg}$, for dystonia; second dose was repeated at 6 hours. There is no incidence of tachycardia or arrhythmia on serial electrocardiac monitoring. Subsequently, the routine blood investigations were sent to laboratory for fur- 
ther process, planned for serum risperidone levels. Gastric lavage sample confirmed the presence of risperidone. An oral diphenhydramine [1 - $2 \mathrm{mg} / \mathrm{kg}$ TID] was given for next two days. Sensorium improved by six hours and speech normalised by $12 \mathrm{hrs}$. Episodes of tori collie and uprolling of eye balls reduced by $6 \mathrm{hrs}$ and completely stopped by $24 \mathrm{hrs}$. Children became asymptomatic by $36 \mathrm{hrs}$. Children were shifted to paediatric ward on day three of admission; and discharged on day 5 of admission and no complications noted at follow up.

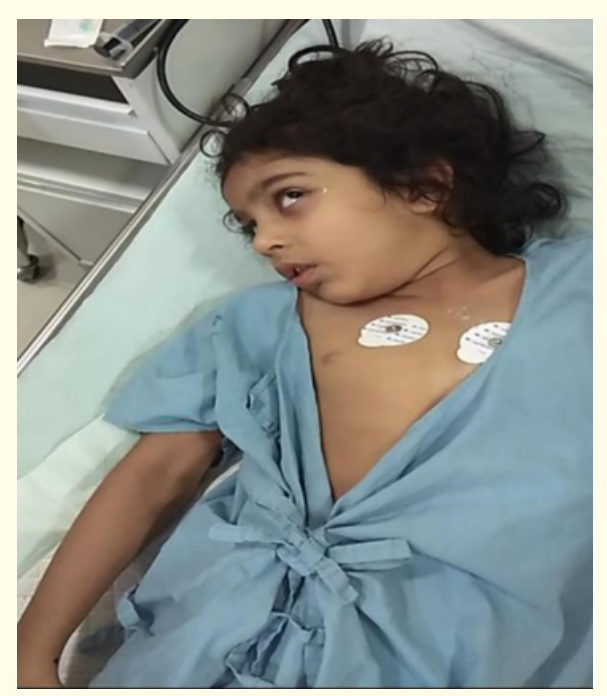

Figure 1: Acute dystoniatorticollis and oculogyric.

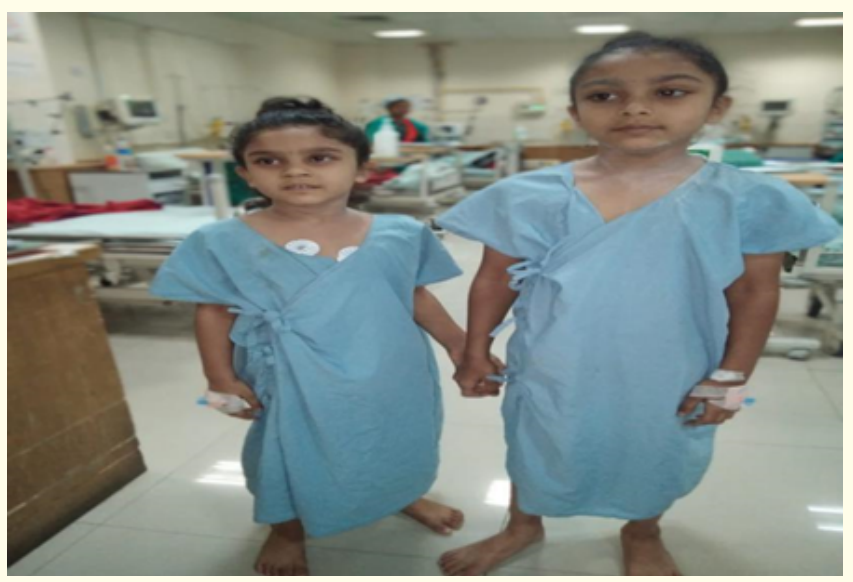

Figure 2: Day 3 of admission, post recovery.

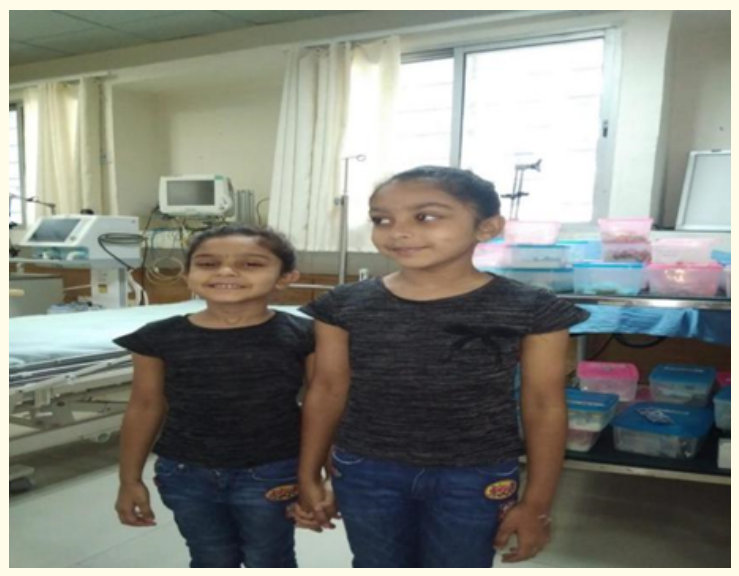

Figure 3: At the time of final discharge.

\section{Discussion}

Risperidone is an atypical antipsychotic approved for the treatment of psychotic disorders in adults in 1994. Its major action is antagonism at serotonin and dopamine receptors and minor action by antagonism at alphaadrenergic receptors and histamine receptors [6-8]. Its primary metabolite is 9-hydroxyrisperidone, which has pharmacological activity similar to that of risperidone. The half-life of the active metabolite is approximately 24 hours [8,9]. Risperidone has proven effective in treating children and adolescents with neuropsychiatric disorder such as autism spectrum, conduct disorders, Tourette syndrome etc [4-8]. Increase in risperidone use has also been paralleled by an increase in the incidence of intentional and nonintentional overdose [2,3]. Although, the incidence of extrapyramidal symptoms were associated with therapeutic risperidone use, its occurrence following overdose is less clearly defined in the literature [10]. The most common adverse reactions associated with risperidone use are drowsiness, slurred speech, altered levels of consciousness, hypertension, tachycardia, electrocardiogram abnormalities, atypical motor behavior, tremors and other extrapyramidal symptoms $[10,11]$ such as pseudoparkinsonism, acute dystonic reactions, akathisia, and tardive dyskinesia [8]. Electrocardiograph abnormalities are in the form of QT-interval prolongation. Central nervous system depression and extrapyramidal symptoms are less commonly associated with Risperidone [11]. The most likely explanation for extrapyramidal symptoms observed with risperidone is due to its antagonism at Dopamine 
(D2) receptors [12]. The dystonia typically involves head and neck muscles and the tongue and, in its severest form, the oculogyric crisis, extraocular muscles, torticollis [8]. The high potency of the dopamine blocker, young age, and prior dystonic reactions may be predisposing factors for drug induced dystonia. Antia identified 40 reports that included 63 patients, ranging in age from 1 day to 17 years of age and found 3 fatalities attributed to risperidone overdose, all in patients who had been prescribed the drug [3]. Catalano reported fifteen year old female child, ingested $110 \mathrm{mg}$ of risperidone with minimal adverse effects. Cheslik and Erramouspe reported a case with accidental ingestion of Risperidone about $4 \mathrm{mg}$ and highlighted the potential for dystonic reactions at low doses [10]. There is a very close similarity between our case and case reported by Cheslik in form of consumption of low dose, yet with Extrapyramidal symptoms. Acri and Henretig reported case series in 1998, which identified four cases of children and adolescents, from 16 months to 15 years, that ingested risperidone. Results were as follows: there were no symptoms that were more serious than dystonia (50\%), tachycardia (25\%), or lethargy $(25 \%)$. Doses ingested ranged from $1 \mathrm{mg}$ in the 16-month-old to $60 \mathrm{mg}$ in a 13-year-old. The patients' conditions resolved with the use of diphenhydramine [10]. Treatment of overdose consists of Gastric lavage with or without charcoal, supportive therapy. There is no specific antidote. Children with Dystonic reactions benefit from anticholinergics. Intravenous diphenhydramine, 1 - $2 \mathrm{mg} / \mathrm{kg} /$ dose, or benztropine may rapidly reverse the drug related dystonia [11]. Dystonias in children should always suggest the possibility of antipsychotic exposure, often as a result of intentional administration by parents [12].

\section{Conclusion}

Physicians and junior doctors to be aware of colour specific dosage of Risperidone, which helps in calculating the consumed amount. Accidental ingestion of low doses of risperidone can also cause extrapyramidal symptoms in children and respond well to treatment with anticholinergic agents.

\section{Bibliography}

1. Isbister GK., et al. "Antipsychotic poisoning in young children: a systemic review". Drug Safety 28 (2005): 1029-1044.

2. Glatstein M., et al. "Severe Extrapyramidal Symptoms After Nonintentional Risperidone Exposure in a Child: Case Report and Review of the Literature". American Journal of Therapeutics 18 (2011): 271-273.
3. Kleigman RM., et al. "Nelson Textbook of Pediatrics". $20^{\text {th }}$ edition 2 (2016): 2892-2894.

4. Kaur D., et al. "Accidental Ingestion of Risperidone in a Toddler with Autism". MGM Journal of Medical Sciences 3.4 (2016): 210-211.

5. Catalano G., et al. "Atypical antipsychotic overdose in the pediatric population". Journal of Child and Adolescent Psychopharmacology 11.4 (2001): 425-434.

6. Moore N and Shukla P. "Risperidone overdose". The American Journal of Psychiatry 154 (1997): 289-290.

7. Brunton LL., et al. “Goodman and Gilman's The Pharmacological Basis of Therapeutics”.13 ${ }^{\text {th }}$ edition. (2018): 283-293.

8. Springfield A and Bodiford E. "An overdose of risperidone". Journal of Analytical Toxicology 20 (1996): 202-203.

9. Cheslik TA and Erramouspe J. "Extrapyramidal symptoms following accidental ingestion of risperidone in a child". Annals of Pharmacotherapy 30 (1996): 360-363.

10. Oslon KR. "Poisoning and Drug Overdose" 7 (2018): 130-132.

11. Bishara D and Taylor D. "Upcoming agents for the treatment of schizophrenia: mechanism of action, efficacy and tolerability". Drugs 68 (2008): 2269-2292.

12. Nasrallah HA. "Atypical antipsychotic-induced metabolic side effects: insights from receptor-binding profiles". Molecular Psychiatry 13 (2008): 27-35.

\section{Assets from publication with us}

- Prompt Acknowledgement after receiving the article

- Thorough Double blinded peer review

- Rapid Publication

- Issue of Publication Certificate

- High visibility of your Published work

Website: www.actascientific.com/

Submit Article: www.actascientific.com/submission.php

Email us: editor@actascientific.com

Contact us: +919182824667 